\title{
HADIS KAO JEDAN OD IZVORA ARAPSKOG JEZIKA
}

\section{Sažetak}

Iako je Muhammed, s.a.v.s., najriecitiji Arap, prve generacije autoriteta arapskoga jezika su se, pri sakupljanju materijala koji bi bio osnova za normiranje ili poturdivanje gramatike $i$ leksike arapskoga jezika, ograničili na Kur'an i predislamsku poeziju kao osnov i izvor tog normiranja.

Prve generacije arapskih lingvista nisu koristile hadis kao standard arapskoga jezika, iako jedan dio hadiskih zbirki spada u period koji se smatra pribvatliivim qa koristenje jezičkog materijala za normiranje arapskoga jezika. Medutim, nakon istrą̌ivanja ustanovit će se da prve generacije nisu odbacivale hadis kao ižvor, nego su Poslanikove, s.a.v.s., hadise koristili pod šrim pojmom „arapskih knjǐ̌evnih tekstova".

Oko pitanja pribvatlivosti hadisa kao iævora arapskoga jęika postoje tri razlicita stava koja smo podrobno iznïjeli u radu.

Akademija za arapski jezile u Kairu je nakon istraživanja donijela kriterije za pribvatanje hadisa kao standarda arapskoga jezik. Kriterije smo naveli na kraju ovoga rada.

Ključne riječi: hadis, standardni arapski jezik, Kur'an, predislamska poezija, iqvori arapskoga jezika, Mubammed, s.a.v.s., Akademija za arapski jezile

\section{Uvod}

Arapi su narod koji je kroz historiju s ponosom štitio svoje vrijednosti i njima se ponosio. Nedvojbeno, jedno od bogatstava kojim su se predislamski Arapi dičili i čuvali jeste jezik kojim govore. Oni su dali sve od sebe kako bi zaštitili arapski jezik ${ }^{2}$, sačuvali njegovu originalnost i čistoću od prodora tuđica iz drugih jezika. Arapskim jezikom se arapski jezikoslovci i filolozi ponose i oni ga revnosno štite od svega što bi moglo ukaljati njegov sjaj i izvornost.

\footnotetext{
${ }^{1}$ Islamski pedagoški fakultet u Bihaću.

2 Pod arapskim jezikom mislimo na standardni, književni arapski jezik, jezik časnog Kur'ana.
} 
Zbog toga su brižno čuvali predislamsku poeziju (الشعر الجاهلي) i jednim dijelom prozu (النثر) iz tog perioda, koje su predstavljale jezgro i osnovu toga jezika. Predislamski Arapi su se međusobno nadmetali u stvaranju novijih i ljepših pjesama na svojim sajmovima (أسواق العرب), a poezija koja je na njima prezentirana bila bi pomno čuvana pisanim, ali i usmenim putem.

Nakon objavljivanja Kur'ana, sve relevantne ličnosti su ga prihvatile kao glavni izvor i standard kojim se mjeri originalnost i ispravnost arapske gramatike i leksike. Ljepota i neimitativnost kur'anskog jezičkog stila ostavila je traga i naprosto plijenila pažnju Arapa upravo na polju jezika u kojem su se tadašnji Arapi smatrali nedostižnim.

Kur'an, predislamska poezija i govorna praksa Arapa tog perioda pa sve do sredine drugog hidžretskog vijeka, predstavljaju jezički materijal iz kojeg su se izvodila ili argumentirala prije izvedena gramatička pravila, ali i leksičko bogatstvo arapskoga jezika.

Međutim, u arapskom jeziku postoje riječi koje su u njega došle isključivo preko hadiskih tekstova. Postavlja se pitanje da li se te riječi mogu smatrati dijelom arapskog jezika ili ne, posebno ako se ima na umu da autoriteti arapskoga jezika iz prvih hidžretskih vjekova nisu koristili hadiske tekstove kao standard za arapski jezik.

\section{Mjesto arapskoga jezika u islamskim naukama}

Izučavanje arapskoga jezika od izuzetnog je značaja za izučavanje islama uopće. Naime, osnovni izvor islama, Kur'an, je objavljen na arapskome jeziku. To potvrđujemo kur'anskim ajetom u kojem Uzvišeni

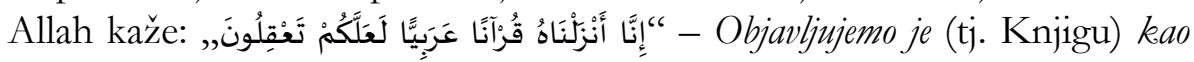
Kur'an na arapskom jeziku da biste razumjeli. ${ }^{3}$ Pored Kur'ana, tradicija Muhammeda, s.a.v.s., (poznatija kao hadis ili sunnet) je izrečena, prenesena i sačuvana isključivo na arapskom jeziku.

Učenjaci arapskoga jezika, bilo da se radi o klasicima ili savremenicima, se slažu oko činjenice da je interes za izučavanje arapskoga jezika tokom prvih vjekova bio motiviran željom da se, prije svega, stane u odbranu Božije riječi - Kur'ana, jer on predstavlja posljednje Božije javljanje čovječanstvu. Sve nauke i discipline koje su

${ }^{3}$ Kur'an, Jusuf, 2. 
nastajale u prvim vjekovima nakon dolaska islama imale su prvenstveno za cilj očuvanje Kur'ana, njegovo razumijevanje, istraživanje njegovih zakona, pravila i normi, a zatim i tradicije Muhammeda, s.a.v.s. Razlog je više nego jasan. Kur'an, kao Božija objava, objavljen je na arapskom jeziku, a Muhammed, Božiji poslanik, je Arap i jezik njegove tradicije bio je arapski jezik. Ako se tome doda da je ogromna većina muslimana i muslimanskih velikana stvarala isključivo na arapskom jeziku i djelovala unutar tog civilizacijskog kruga nekoliko vjekova, onda je povezanost islama s arapskim jezikom više nego očita i razumljiva.

Međusobni odnos islamskih nauka (a tu podrazumijevamo sve nauke proistekle iz njega) i arapskoga jezika karakteriše uzajamna korist, jer je islam uzdigao vrijednost arapskoga jezika i sačuvao ga od iskrivljavanja i izumiranja, prvenstveno kroz Kur'an i tradiciju Muhammeda, s.a.v.s. Zauzvrat, arapski jezik je bogatstvom izraza i fleksibilnošću svojih značenja pomogao da islam bude shvaćen kao fleksibilna i univerzalna vjera. ${ }^{4}$

\section{Sunnet $i$ hadis}

Mnoštvo je sinonima koji ukazuju na ono što se prenosi od riječi, postupaka ili događaja koji su se desili za vrijeme života Muhammeda, s.a.v.s. Tu se najviše ističu dva termina, a to su sunnet i hadis. Njihovo filološko značenje je različito, jer sunnet označava put, način života $i$ metod, dok hadis označava nešto što je novo (suprotno pojmu staro) ili govor. ${ }^{5}$ Međutim, njihovo terminološko značenje je skoro identično, a ono glasi ovako: sve sto je preneseno od Muhammeda, s.a.v.s.,bilo ono verbalnog, praktičnog ili odobravajúceg karaktera, osim Kur'ana. ${ }^{6}$

Iako ova dva termina važe kao sinonimi, u ovom radu ću se opredijeliti za termin hadis iz više razloga:

1. zato što većina autora koristi upravo ovaj termin kada govori o ovoj temi,

4 Više o ovoj temi vidjeti: Jahić, Mustafa, Arapski jezik u islamskim naukama, Gazi Husrev-begova biblioteka, Sarajevo, 2012.

5 Nakičević, Omer, Uvod u hadiske znanosti, Fakultet islamskih nauka, Sarajevo, 1997., treće dopunjeno izdanje, str. 5-6.

${ }^{6}$ Topoljak, Sulejman, Uvod u metodologiju islamskog prava, Fakultet islamskih studija, Novi Pazar, 2006., str. 159. 
2. zato što po mišljenju jednog dijela autora hadis ima specifičnije značenje od sunneta,

3. zato što sunnet može imati svoje drugo terminološko-pravno značenje, kao što je pravni status nekog djela, što termin hadis nema.

Hadis možemo dijeliti po mnogim osnovama, ali iz ove definicije se dâ razumjeti da se hadis sastoji od: a) verbalnih izreka, b) praktičnih Poslanikovih, s.a.v.s., postupaka i c) predaje koje sadrže odobravanja događaja ili postupaka koji su se desili u prisustvu ili odsustvu Poslanika, s.a.v.s., pa ih je on osudio ili šutnjom odobrio.

Međutim, hadis možemo dijeliti i po osnovu broja prenosilaca u svakom lancu, pa ga na osnovu toga dijelimo na mutevatir ${ }^{7}$, âhâd ${ }^{8}$ ili mešhu $r^{?}$, a ova podjela će biti značajna u nekim segmentima ovoga rada.

\section{Kodifikacija hadisa}

Ashabi Allahovog Poslanika, s.a.v.s., su slušali hadis i usmeno ga prenosili ljudima u svojoj okolini, a oni koji su ga čuli, također, usmeno su ga prenosili ostalima, tako da se stvarao lanac prenosilaca koji je s koljena na koljeno i od osobe do osobe prenosio Poslanikove, s.a.v.s., hadise narednim generacijama. Tako je ostalo sve dok se nisu počeli zapisivati i kodificirati hadisi u manje ili veće, manje ili više poznate hadiske zbirke. Prva zvanična kodifikacija hadisa bila je na osnovu naredbe halife Omera ibn Abdulaziza (u. 720.). Naime, taj emevijski halifa je pisao svom namjesniku u Medini, Ebu Bekru Muhammedu ibn Omer ibn Hazmu (u. 738.) da počne sa kodifikacijom izreka Muhammeda, s.a.v.s., jer se pobojao nestanka (islamske) nauke i smrti (islamskih) učenjaka. Isto je napisao i Muhammedu ibn Šihabu ezZuhriju (u. 741.), jer je jedina pisana knjiga u to doba bio Kur'an.

Među najstarijim pisanim dokumentima koji sadrže hadise - izreke Muhammeda, s.a.v.s., jeste Malikova (u. 796.) zbirka hadisa i islamskopravnih mišljenja poznata kao Muvetta (الموطا)( Sve navedeno nas vodi do

\footnotetext{
${ }^{7}$ Mutevatir predaja je ona koju prenosi veliki broj ljudi u svim generacijama tako da je nemoguće posumnjati u njegovu istinitost.

8 Áhäd hadis je onaj hadis čiji broj prenosilaca od Allahovog Poslanika, s.a.v.s., u prva tri vijeka nije dostigao stepen mutevatir hadisa.

9 Mešhur je onaj hadis kojeg u prvom hidžretskom vijeku prenose jedan ili dva prenosilaca, dok ga u narednim vjekovima prenosi veći broj koji dostiže broj prenosioca mutevatir hadisa.
} 
zaključka da je početak kodifikacije hadisa bio početkom drugog hidžretskog vijeka, što znači da se to desilo unutar perioda poznatijeg kao period jezičke čistoće.

Razlog nepostojanja primjera kodifikacije sunneta $u$ ranijem periodu leži u Muhammedovoj, s.a.v.s., zabrani svojim prijateljima da pišu bilo šta mimo Kur’ana, da se ne bi pomiješalo sa Kur’anom.

I pored toga, jedan broj ashaba je zapisivao hadise koje bi čuo od Poslanika, s.a.v.s. To su radili zbog činjenice da se zabrana odnosila na samo neke ashabe ili da oni koji su ih pisali nisu znali da zabrana uopće postoji. $\mathrm{Na}$ taj način je jedan manji broj hadisa zapisan za vrijeme Muhammeda, s.a.v.s., u manje zbirke, kao što su zbirke po imenu EsSâdika i Es-Sahîfa.

\section{Stavovi arapskih filologa}

Kao što smo to u uvodu i istakli, arapski filolozi nemaju jedinstven stav po pitanju korištenja hadiskih tekstova kao standarda u arapskome jeziku. Mi ćemo u ovom radu iznijeti njihove stavove i potkrijepiti njihove argumente, a zatim ćemo se osvrnuti na iste i napraviti kraću raspravu u kojoj ćemo dodatno pojasniti oko čega se oni, zapravo, razilaze, a oko čega slažu.

Postoje dvije skupine arapskih filologa koji imaju dva oprečna stava glede korištenja hadiskih tekstova kao izvora gramatike i leksike arapskoga jezika. Svaka od tih skupina ima svoju argumentaciju kojom podupire svoj stav. Mi ćemo iznijeti argumente obje skupine i u jednom od narednih poglavlja u vidu kraće rasprave pokušati pronaći ispravnije mišljenje.

Prva skupina smatra da, iako je hadis koji je mutevatir-predajom prenesen narednim generacijama validan argument, preneseni hadisi zapravo ne predstavljaju doslovan govor Muhammeda, s.a.v.s. Po njihovom mišljenju, hadis nije mjerodavan izvor za gramatiku i leksiku arapskoga jezika, a ovaj stav od autoriteta u arapskom jeziku su zastupali: Ebu Hajjan (u. 1023), Halil ibn Ahmed (u. 791), Sibevejh (u. 796), ElKisa'i (u. 805), Es-Sujuti (u. 1505.) i drugi. Oni svoj stav podupiru slijedećim argumentima:

Prvo: Prve generacije arapskih filologa u svojim djelima nisu koristile hadis kao izvor arapskoga jezika, a to nam dovoljno govori da su 
zastupali stav da ga ne treba tretirati kao takvog i da se treba ograničiti na već spomenute izvore arapskoga jezika, poput Kur'ana, predislamske poezije i govorne prakse tadašnjih Arapa.

Drugo: Period do kojeg je prihvatljivo korištenje jezičke prakse Arapa kao argumenta jeste početak druge polovice drugog hidžretskog vijeka (167. h. g. ili 783. g. prema gregorijanskom kalendaru), a kodifikacija većine hadiskih zbirki bila je dosta kasnije, što nam jasno govori da hadis ne ispunjava uslove da bi imao status izvora koji će poslužiti za normiranje arapske leksike ili gramatike. Zbog toga su arapski filolozi postavili spomenutu godinu kao kraj perioda iz kojeg se prihvatala jezička praksa kao standard arapskog jezika.

Nakon tog perioda primjetno je da se javljaju gramatičke greške kod osoba koje govore arapskim jezikom, posebno zbog činjenice da je veliki broj nearapa primio islam i počeo koristiti arapski jezik jer je on jezik časnog Kur'ana i islamskih obreda. To je najviše dolazilo do izražaja kod osoba koje su bili iz miješanih brakova (Arapa sa nearapima) i kod Arapa koji su, zbog činjenice da borave na rubnim područjima, dolazili u čest kontakt sa nearapima i tako iskvarili svoj jezik.

Tréce: Pod pretpostavkom da se prihvati hadis kao izvor arapskoga jezika, susrećemo sa pregrštom primjera prenošenja hadisa prema značenju, tako da imamo primjer predaje u kojoj se jedan hadis u jednom slučaju prenosi na pet načina, što jasno ukazuje da je taj hadis prenesen prema značenju, a ne doslovno. Kao primjer toga navode slijedeći hadis:

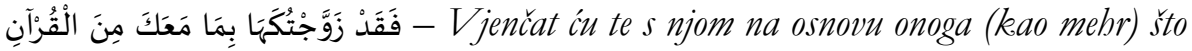
znaš napamet od Kur'ana. ${ }^{10}$ Ovaj hadis je prenesen u nekoliko različitih

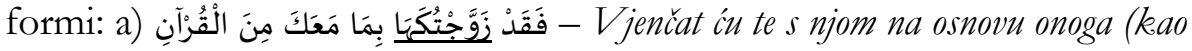

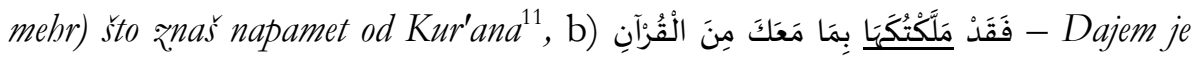

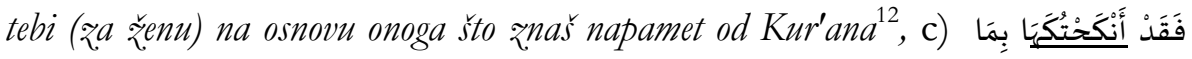
- Vَjenčajem je za tebe na osnovu onoga śto znaš napamet od

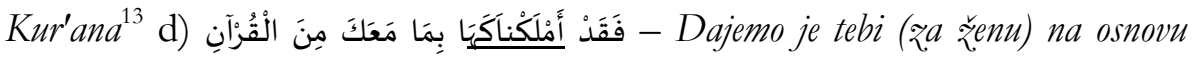
onoga što znaš napamet od Kur'ana. ${ }^{14}{ }^{15}$ Sve ove verzije hadisa ukazuju da su

\footnotetext{
10 Bilježi ga Buhari (5135).

${ }^{11}$ Bilježi ga Buhari (5135).

12 Bilježi ga Buhari (5141).

13 Bilježi ga Buhari (5149).

${ }^{14}$ Bilježi ga Buhari (5121).

15 Arapski jezik u islamskim naukama, str. 372.
} 
ih prenosioci prenosili prema značenju, a to znači da su uvrštavali sinonime koje su oni smatrali adekvatnom zamjenom za izraz kojeg je koristio Muhammed, s.a.v.s., prilikom izricanja hadisa $i$ ti hadisi ne odražavaju doslovan govor Muhammeda, s.a.v.s., nego njegov smisao.

Druga skupina smatra da je hadis meritoran izvor gramatike i leksike arapskog jezika, a ovaj stav su zastupali: Ibn Malik (u. 1274.), Ibn Hišam (u. 1359.), Ibn Faris (u. 1005.), Ibn Džinni (u. 1001.) i drugi. Oni svoj stav podupiru slijedećim argumentima:

Prvo: Muhammed, s.a.v.s., govorio je najčišćim arapskim jezikom i bio je najrječitiji Arap, tako da njegove riječi mogu poslužiti kao standard arapskog jezika. Jedna od njegovih karakteristika i odlika jeste i to da je njegov govor krasila jezgrovitost i sadržajnost (جوامع الكلم), što on u nekoliko hadisa ističe, što ide u prilog prihvatanju njegovih riječi kao izvora arapskoga jezika.

Drugo: Osnova je da su prenosioci hadise prenosili doslovno i tako je bilo u većini slučajeva. Svakako, postoji mogućnost da se jedan broj hadisa prenio prema značenju, posebno kada se radi o dužim hadisima, ali tu treba imati na umu da se nastojalo hadise prenijeti doslovno i da prenosioci spadaju u Arape koji su živjeli u vrijeme koje slovi kao period iz kojeg se leksika prihvatala kao općeprihvatljiva (عصر الاحتجاج اللغوي), kao i podatak da je značajan broj prenosioca imao hadise zabilježene i da su ih prenosili iz tih zabilješki. ${ }^{16}$ Također, značajan broj hadiskih zbirki je kodificiran prije javljanja gramatičkih grešaka (اللحن), a jedan manji broj hadisa je zapisan čak za vrijeme Muhammeda, s.a.v.s., poput zbirki EsSâdika i Es-Sahîfa.

Tré́e: Ukoliko se napravi analizira, doći će se do zaključka da su prve generacije autoriteta arapskog jezika koristile hadis kao standard, ali ne kao hadis, nego kao širi pojam govora Arapa (قول العرب) ili stari knjǐ̌erni tekstovi (النصوص الأدبية القديمة), što podrazumijeva da su smatrali da je ispravno koristiti tu vrstu historijskog naslijeđa kao standard arapskoga jezika. Veliki broj autoriteta arapskoga jezika su koristili hadis kao izvor i

${ }^{16}$ Muhtar Omer, Ahmed, El-Bahsul-lugavi indel-arab, Alemul-kutub, Kairo, 1988., str. 36. 
standard u svojim djelima, a neki od njih su: Halil ibn Ahmed $^{17}$, ElAsma'i ${ }^{18}$, Ibn Faris ${ }^{19}$, El-Dževheri' ${ }^{20}$, Ibn Malik ${ }^{21}$ i drugi.

Ceturto: Zanimljivo je da su pojedini autoriteti arapskog jezika, poput Halil ibn Ahmeda, koristili hadise kao standard u leksikografiji, a da su ih u gramatici izostavljali. To može biti samo argument da su hadisi jedan od izvora arapskoga jezika i da neargumentiranje njima u jednom segmentu ne podrazumijeva da ih nije dozvoljeno koristiti u drugom, posebno ako to sâm autor nije izričito naglasio.

Peto: Većina hadisa ima jači lanac prenosilaca od arapske predislamske poezije, ali i pored toga se predislamska poezija prihvata, a hadis kao izvor i standard arapskog jezika zanemaruje i dovodi u pitanje njegova vjerodostojnost. ${ }^{22}$

Šesto: Ukoliko je došlo do grešaka pri prenošenju pojedinih hadisa, to ne treba da bude razlog da se hadis u cijelosti odbaci kao jezičko blago neprocjenjive vrijednosti, ali i kao izvor i standard arapskoga jezika.

Ono što se može primijetiti jeste da prvo mišljenje karakteriše činjenica da se radi o autoritetima koji su živjeli u prvim hidžretskim vjekovima, i to predstavlja prvu etapu razvoja gramatičkih istraživanja, dok u drugoj etapi, koja je uslijedila kasnije (oko VII hidžretskog vijeka), autoriteti arapskoga jezika iz tog perioda naginju mišljenju koje prihvata hadis kao izvor jezičkog materijala u arapskom jeziku, ali i druge izvore poput analogije i slično.

Pored ova dva postoji treća skupina koju predvodi Ebu Ishak ešŠatibi (1388.) koji predstavlja sredinu između dva prethodno iznesena stava. On pravi distinkciju između hadisa koji su preneseni doslovno i dugih hadisa koji su preneseni po značenju, gdje prvu grupu prihvata, a drugu ne. On kritikuje one koji ne prihvataju argumentaciju hadisima u arapskom jeziku i pita se kako mogu prihvatati govor neobrazovanih Arapa i njihovu predislamsku bestidnu poeziju. ${ }^{23}$

\footnotetext{
${ }^{17}$ Ibn Ahmed, Halil, El-Ajn, drugo izdanje, 1/70.

${ }^{18}$ El-Asma'i, El-Addad, Bejrut, 1913., str. 23.

${ }^{19}$ Ibn Faris, Ahmed, Mu'džemul-mekajis fil-luga, Darul-fikr, Bejrut, 1994., str. 52.

${ }^{20}$ El-Dževheri, Taď̌ul-luga ve sibahul-arebijje, Darul-ilm lil-melajin, Bejrut, 1/35.

21 Ibn Malik, Ševabidut-tevdih, Mektebe Ibn Tejmijje, 1413. h.g., str. 54.

22 El-Bahsul-lugavi indel-arab, str. 36.

${ }^{23}$ Fedžal, Mahmud, El-Hadis en-nebevi fi en-nabv el-arebi, Edvâ' es-selef, Er-Rijad, 1997. drugo izdanje, str. 9.
} 


\section{Odnos prvih generacija arapskih lingvista prema hadisu}

Ono oko čega se slažu autoriteti arapskog jezika danas jeste da značajan dio savremenih arapskih lingvista prihvata hadis kao standard i izvor arapskog jezika, te da je tâ pojava počela uzimati maha od XV vijeka pa sve do danas.

To nas vodi do zaključka da je bitno dodatno istražiti odnos prvih generacija spram hadisa kao standarda i izvora arapskoga jezika, jer većina narednih generacija svoje neprihvatanje istog izvora opravdava činjenicom da je to bila praksa prvih generacija.

Nakon istraživanja prakse prvih generacija možemo zaključiti slijedeće:

a) prve generacije arapskih lingvista su koristile hadis kao standard arapskog jezika, ali to nisu naglašavale, nego su ih koristile u vidu starih arapskih tekstova,

b) nigdje niko od njih izričito ne odbija hadis kao standard arapskoga jezika,

c) bitno je napomenuti da je uzrok slabog ili rijetkog oslanjanja autoriteta prvih vijekova na hadis činjenica da hadiske zbirke nisu bile rasprostranjene među njima, s obzirom da su nastajale znatno kasnije,

d) činjenica da su sakupljači hadisa bili u Hidžazu (Mekka i Medina), a da su najveći jezički lingvisti bili u Iraku (Bagdad, Kufa, Basra), dovoljno govori da je trebalo vremena da se te zbirke prošire islamskom državom.

Prema tome, ono što pojedini autoriteti danas koriste kao argument da prve generacije arapskih lingvista nisu koristile hadis nema uporišta zbog svega prethodno navedenog.

\section{Rasprava}

Nakon prezentiranih stavova, argumenata i pojašnjenja vezanog za stav autoriteta arapskoga jezika u prvim hidžretskim vjekovima, dolazimo do neophodne rasprave ili osvrta na argumente obje strane kojima bi se pojasnile tačke oko kojih se mišljenja slažu, a šta je to oko čega se oni, ustvari, razilaze.

Ono oko čega se sva mišljenja slažu jeste da prihvataju korištenje mutevatir-hadisa prilikom argumentacije hadisima u arapskom jeziku, jer 
nema sumnje da su oni doslovno preneseni od Poslanika, s.a.v.s. Također, nema razilaženja oko hadisa koji su ostali dokumentovani pisanim tragom, poput Poslanikovih, s.a.v.s., pisama ili ugovora.

Pitanja oko kojih se razilaze mišljenja mogu se svesti na dvije tačke: a) prenošenje hadisa prema značenju, b) činjenica da su pojedini prenosioci živjeli u periodu pojave gramatičkih grešaka, kojeg arapski lingvisti ne prihvataju kao meritornog za korištenje jezičke građe. Upravo ova dva pitanja predstavljaju okosnicu argumenata skupine koja ne dozvoljava korištenje hadisa za argumentaciju u arapskom jeziku.

\section{Prenošenje hadisa po značenju}

Činjenica je da je jedan broj hadisa prenesen prema značenju, posebno je to slučaj sa dužim hadisima. Bitno je napomenuti da nije bilo primjera prenošenja hadisa prema značenju u zbirkama koje su tada bile već kodificirane. Ukoliko se ne radi o prenošenju hadisa prema značenju iz pamćenja, onda treba praviti razliku između prve i narednih generacija prenosilaca. Ako se radi o prvoj generaciji, oni su bili sposobni zamijeniti riječ ili frazu adekvatnim sinonimom, jer su odlično poznavali standardni arapski jezik kojeg su bez greške koristili. Međutim, ako se radi o narednim generacijama, hadiski stručnjaci su uslovljavali da osoba koja prenosi hadis prema značenju dobro poznaje semantiku arapskoga jezika i da je dobro upoznata sa onim što bi moglo izmijeniti ili oslabiti značenje neke od riječi. U protivnom, hadis bi bio okarakterisan kao slab.

\section{Period pojave gramatičkih grešaka}

Period do kojeg je prihvatljivo korištenje jezičke prakse kao argumenta jeste početak druge polovice drugog hidžretskog vijeka, a period koji mu je prethodio poznat je kao period jezičce čistoće - عصر الاحتجاج اللغوي. Nakon tog perioda veliki broj nearapa primio je islam i počeo koristiti arapski jezik što je dovelo do pojave grešaka u arapskom jeziku. Pored njih bilo je i slučajeva osoba koje su bile iz miješanih brakova (Arapi i nearapi), te Arapa koji su dolazili u čest kontakt sa nearapima.

Ukoliko analiziramo nastanak hadiskih zbirki, naći ćemo da je jedan broj njih nastao tokom perioda jezičke čistoće, poput Malikove Muvette, te se njegova zbirka, ali i ono što je Ez-Zuhri kodifikovao po 
naredbi tadašnjeg halife Omera ibn Abdulaziza, nedvojbeno može smatrati općeprihvatljivim.

Istina, preostale najpoznatije zbirke su sakupljene u dva naredna vijeka, ali nije presudno da su se desile promjene u tekstu hadisa, jer je broj prenosilaca hadisa u ovim hronološkim nizovima znatno veći, posebno ako se uzme u obzir da je značajan broj hadisa već postao dio svakodnevne prakse tadašnjih muslimana - kroz svakodnevni život, vjerske obrede, vjerske manifestacije, kraći sažeti hadisi, itd. Također, govor pojedinih sredina i osoba je ostao općeprihvatljiv za jezičke autoritete, iako nisu živjeli unutar tog perioda, kao što je slučaj sa vjerskim autoritetom Muhammed ibn Idrisom eš-Šafijom ili plemenima koja žive u ruralnim područjima u kojima gramatičke greške nisu uzele maha ni narednih nekoliko vjekova.

\section{Zaključak}

1. Hadiski tekstovi mogu služiti kao standard arapskog jezika, pod uslovima koje je pojasnila Akademija za arapski jezik u Kairu.

2. Akademija za arapski jezik u Kairu je, oslanjajući se na istraživanje Muhammeda Hadira Husejna, utvrdila da se hadisi kodificirani u prvom periodu sakupljanja sunneta, među kojima su šest poznatih vjerodostojnih zbirki i zbirke nastale prije njih, mogu koristiti u gramatičkim argumentiranjima ako pripadaju jednoj od slijedećih vrsta hadisa: a) poznati hadisi preneseni višebrojnim vjerodostojnim hronološkim nizovima prenosilaca (mutevatir i mešhur), b) hadisi koji se جوامع ( kariste u vjerskim obredima, c) kraći hadisi jezgrovitog sadržaja (الكلم), d) hadisi koji predstavljaju Poslanikova izdiktirana pisma i ugovore, e) hadisi kojima se Poslanik, s.a.v.s., obraća sugovornicima u upravnom govoru, f) hadisi koje bilježe prenosioci poznati po tome da nisu dozvoljavali prenošenje hadisa prema značenju, poput Kasima ibn Muhammeda i Ibn Sirina, g) hadisi koji se prenose preko više različitih hronoloških nizova prenosilaca u jedinstvenoj formi.

3. Prve generacije autoriteta arapskoga jezika koristile su hadis kao standard, ali ne kao hadis, nego kao širi pojam govora Arapa (قول العرب) ili stari knjižrevni tekstovi (النصوص الأدبية القديمة), što podrazumijeva da su smatrali da je ispravno koristiti tu vrstu historijskog naslijeđa kao standard arapskoga jezika. 
4. Ukoliko analiziramo nastanak hadiskih zbirki, naći ćemo da je jedan broj njih nastao tokom tog perioda, poput Malikove Muvette, te se njegova zbirka, ali i ono što je Ez-Zuhri po naredbi tadašnjeg halife Omera ibn Abdulaziza, nedojbeno može smatrati općeprihvatljivim.

5. Ono oko čega se sva mišljenja slažu jeste da prihvataju korištenje mutevatir hadisa prilikom argumentacije hadisima u arapskom jeziku, jer nema sumnje da je on doslovno prenesen od Poslanika, s.a.v.s. Također, nema razilaženja oko hadisa koji su ostali dokumentovani pisanim tragom, poput Poslanikovih, s.a.v.s., pisama ili ugovora.

6. Hadiski stručnjaci su uslovljavali da osoba koja prenosi hadis prema značenju dobro poznavanje sematiku arapskoga jezika i da je dobro upoznata sa onim što bi moglo izmijeniti ili oslabiti značenje neke od riječi.

\section{Literatura:}

1. Kur'an.

2. Buhari, Muhammed ibn Ismail, Sahihul-Buhari, Dar Ibn Kesir, Damask, 2002.

3. El-Asma'i, El-Addad, Bejrut, 1913.

4. El-Dževheri, Taď̌ul-luga ve sibahul-arebijje, Darul-ilm lil-melajin, Bejrut.

5. Fedžal, Mahmud, El-Hadis en-nebevi fi en-nabv el-arebi, Edvâ' es-selef, Er-Rijad, 1997.

6. Husein, Muhammed Hudr, Dirasat fi el-arebijje ve tarihiha, El-Mekteb el-islami, Damask, 1960.

7. Ibn Ahmed, Halil, El-Ajn, drugo izdanje.

8. Ibn Faris, Ahmed, Mu'džemul-mekajis fil-luga, Darul-fikr, Bejrut, 1994.

9. Ibn Malik, Ševabidut-tevdih, Mektebe Ibn Tejmijje, 1413. h. g.

10. Jahić, Mustafa, Arapski jezik u islamskim nankama, Gazi Husrev-begova biblioteka, Sarajevo, 2012.

11. Muhtar Omer, Ahmed, El-Bahsul-lugavi indel-arab, Alemul-kutub, Kairo, 1988.

12. Nakičević, Omer, Uvod u hadiske znanosti, Fakultet islamskih nauka, Sarajevo, 1997.

13. Topoljak, Sulejman, Uvod u metodologiju islamskog prava, Fakultet islamskih studija, Novi Pazar, 2006. 
Hajrudin Hodzic, MA

\section{HADITH AS A SOURCE OF ARABIC LANGUAGE}

\section{ABSTRACT}

Although Muhammad, peace be upon him, was the most eloquent Arab, the first generation of authorities in the field of Arabic language restricted only the Qur'an and pre-Islamic poetry as the core and source during the process of gathering material used for standardization and certification of the grammar and lexicon of Arabic language.

The first generation of Arab linguists have not used the Hadith as a standard for Arabic language, although one part of Hadith collections belong to the period that is considered as a acceptable source of language material for standardization of Arabic language. However, research have confirmed that the first generation of linguists did not reject Hadith as a source, but they used it as a broader term of "Arabic literary texts."

There are three different views regarding the question of acceptability of Hadith as a source of Arabic language and they are represented in detail in this paper.

The Academy for Arabic Language in Cairo has mentioned the criteria for acceptance of Hadith as a standard for Arabic language as a result of conducted research.

These criteria been stated at the end of this paper.

Keywords: Hadith, standard Arabic language, Qur'an, pre-Islamic poetry, sources of Arabic language, Mubammad, peace be upon him, the Academy of the Arabic language 


$$
\text { م. خير الدين هوجيتش }
$$

\section{الحديث النبوي باعتباره أحد مصبادر اللغة العربية}

\section{الخلاصة}

وإن كان محمد صلى الله عليه وسلم أفصح العرب، فإن الأجيال الأولى من علماء

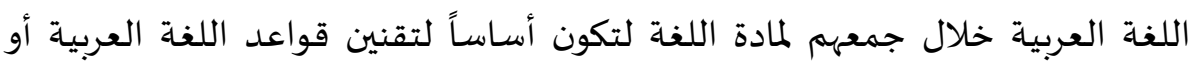

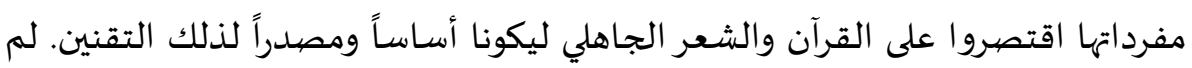

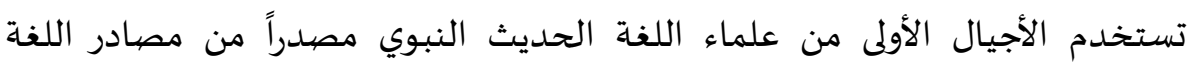

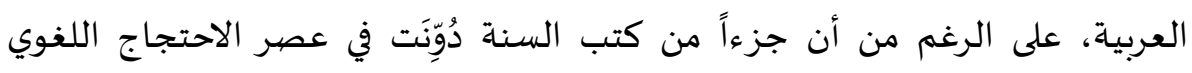
الصالح لجعلها مادة التقنين.

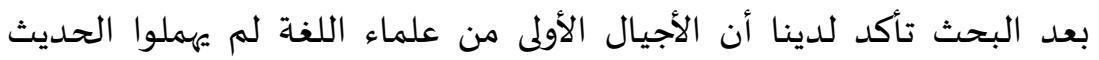

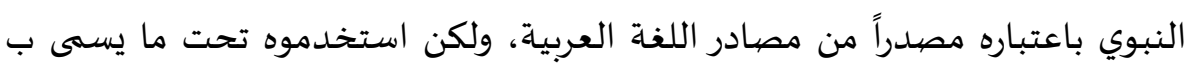
"نصوص أدبية قديمة".

هناك ثلاثة آراء حول مسألة الاحتجاج بالحديث النبوي في مسائل اللغة وقد أوردناها بالتفصيل.

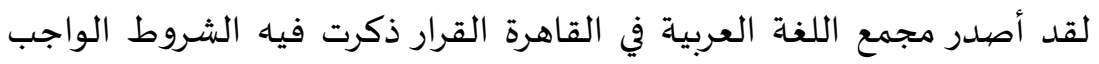
توفرها في الاحتجاج بالحديث النبوي في مسائل اللغة العربية وقد أوردناها في نهاية هذا البحث.

الكلمات الرئيسة: الحديث النبوي، اللغة العربية الفصحى، القرآن، الشعر

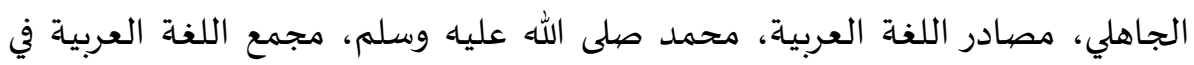
القاهرة 